\title{
Advanced Materials based on the Recycled Polyvinyl Butyral (PVB)
}

\author{
Lucia Knapčíková ${ }^{*}$, Svetlana Radchenko ${ }^{2}$, Darina Dupláková ${ }^{3}$, \\ Michal Hatala ${ }^{2}$ \\ \{lucia.knapcikova, \\ svetlana.radchenko, darina.duplakova, michal.hatala \} @tuke.sk \\ $1^{*}$ Technical University of Košice, Faculty of manufacturing technologies with a seat in \\ Prešov, Department of industrial engineering and informatics, Bayerova 1, 08001 Prešov, \\ Slovak Republic \\ ${ }^{2}$ Technical University of Košice, Faculty of manufacturing technologies with a seat in \\ Prešov, Department of automobile and manufacturing technologies, Bayerova 1, 08001 \\ Prešov, \\ Slovak Republic \\ ${ }^{3}$ Technical University of Košice, Faculty of manufacturing technologies with a seat in \\ Prešov, Department of process engineering, Bayerova 1, 08001 Prešov, \\ Slovak Republic
}

\begin{abstract}
The aim of this paper is to describe the use of recycled polyvinyl butyral (PVB) after windscreen recycling. Homogenization of recycled PVB and test samples, were pressed according to DIN EN ISO 527-1. Recycled PVB is an important ingredient in the production of new materials, which are characterized by very good elasticity, adhesion to different surfaces and good water resistance. Tests were performed at room temperature 22 ${ }^{\circ} \mathrm{C}$ and $60 \%$ humidity. The homogenization process lasted $15 \mathrm{~min}$. The advantage of the PVB is its high compatibility with other polymers, as well as very good possibilities for the processing of various thermoplastics.
\end{abstract}

Keywords: waste windscreen, recycling, progressive materials

\section{State of the art}

Polyvinyl butyral (PVB) [1] is a special resin material, mainly used as a raw material for glass laminated safety glass in cars and in the building industry. Application is mainly for high-rise buildings. PVB currently produces several 
companies in Europe and the world, each under its business name. In addition to the main application and thus the use of PVB films, PVB resins are used for the production of paints, structural adhesives, dry toner paints and as binders for ceramics and composite fibers. [2] The PVB film has a number of outstanding features such as high tensile strength, impact resistance, transparency and flexibility, which is particularly useful in the production of safety glass. Due to the alcohol, ester and acetate bond content, PVB films [3] can hold the glass firmly, even if the glass breaks. The glasses adhere to the interlayers of PVB film to prevent breakage. [3], [4] Revenues of primary end-users of polyvinyl butyral are dependent on the performance of the general economy, especially for safety glass, which is so necessary in the automotive and construction industry - in architecture.

In the market, polyvinyl butyral resins are highly concentrated and are the domain of four companies - Eastman, Sekisui, DuPont and Kuraray [5] , [6] PVB is exported to countries with the expansion of car production. In most advanced countries, such as the United States, Western Europe and Japan, but also in the Middle East, demand for PVB is still high. In the context of the use of the security foil, it was preferred primarily to areas of architecture, such as laminated safety glass. PVB is a huge potential for the emerging market. [4], [5] The following figure (Fig.1) shows the place of insertion of the polyvinyl butyral sheet between the glass sheets and the formation of the safety glass (or safety windscreen).

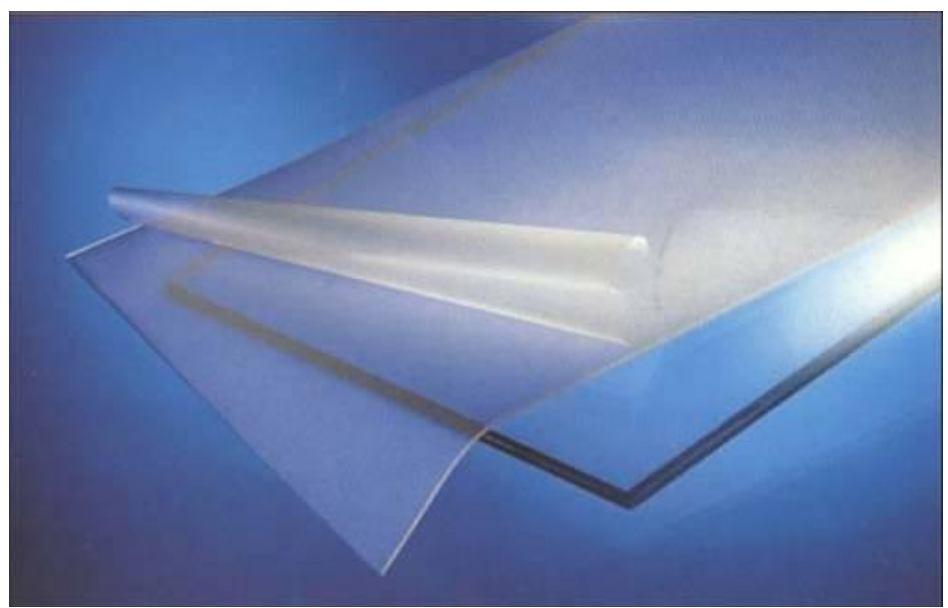

Fig. 1. Polyvinyl butyral film as a part of safety glass [8]

PVB film is one of the most important parts in the interlayer of a windscreen or safety glass. [4] Laminated glass, commonly used in architecture and the automotive industry, has a protective interlayer, most of which is a PVB that forms a fuse between two glass sheets. [5] A study on Transparency Market Research shows that land transport was the largest end-user of the PVB segment of the market, accounting for more than $45 \%$ of the use rate than in 2014. [6] Figure 2 shows in 
detail the condition after the windscreen was damaged by impact. It can be seen that the glass does not break, it only shatters and holds the spoil. The material that the glass layers hold together is a polyvinyl butyral foil.

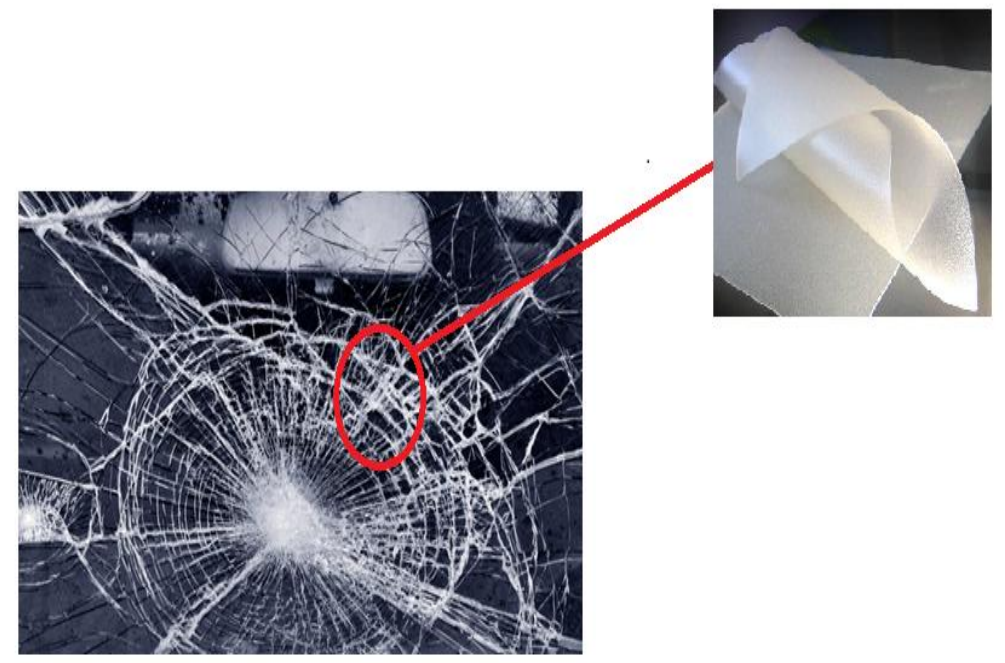

Fig.2. Polyvinyl butyral film as a part of safety windscreen [8]

With regard to solar energy, there is a prediction that the fastest growing area of the end-user PVB, with respect to the compound annual growth rate, is projected to increase by more than $6 \%$ between 2015 and 2015- 2023. [7] In terms of volume of PVB produced, the Asian region in 2014 thus contributed to more than $35 \%$ of the share of PVB use in the global market. The use of PVB film in Latin America, the Middle East and Africa market is expected to grow significantly over the next eight years, mainly due to the increase in land transport and construction as end users. [8]

\section{Materials and methods}

Polyvinyl butyral, which forms is a safety interlayer in windscreens or glasses of buildings, takes the form (Fig.3) of flakes having dimensions of $2 \mathrm{~mm}-20 \mathrm{~mm}$ and a thickness of $0,5 \mathrm{~mm}-1,5 \mathrm{~mm}$. 


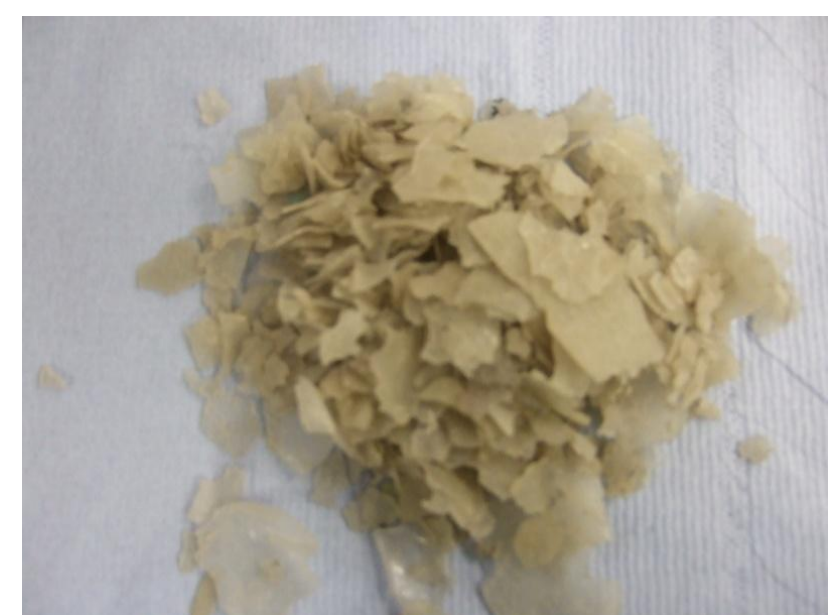

Fig.3. Recycled polyvinyl butyral in the flakes form [12]

This recycled polyvinyl butyral was contaminated (dust, glass fragments), so it was necessary to thoroughly wash the material and dry it before starting laboratory work. By the laboratory work was used as PVB flakes. [9] The recycled polyvinyl butyral used in the research has the following parameters (Table 1).

Table 1. Material characteristics of recycled polyvinyl butyral

\begin{tabular}{|l|c|}
\hline \multicolumn{2}{|c|}{ PVB-polyvinyl butyral, recycled } \\
\hline Form & flakes \\
\hline Colour & colourless \\
\hline Size & $20-30 \mathrm{~mm}$ \\
\hline Purity & More as $97 \%$ \\
\hline Impurities & Less as $3 \%$ \\
\hline Residual humidity & ca. $2 \%$ \\
\hline $\begin{array}{l}\text { Contents of glass } \\
\text { particles }\end{array}$ & Less as $2 \%$ \\
\hline Fire point & \\
\hline Tg & $130{ }^{\circ} \mathrm{C}-170^{\circ} \mathrm{C}$ \\
\hline Viscosity (dynamic) & $100-175 \mathrm{~m} \mathrm{Pa*} s$ \\
& $(\mathrm{DIN} 53015)$ \\
\hline MVR (Melt Volume Rate) & $6-7 \mathrm{~cm}^{3} / 10$ \\
& $\mathrm{~min}$ \\
\hline MFR (Melt Flow Rate) & $5-6 \mathrm{~g} / 10 \mathrm{~min}$ \\
\hline
\end{tabular}


Granulate material is a more convenient and convenient alternative to the preparation of composite materials. [10] , [11], [15] Polyvinyl butyral as thermoplastic material is soluble in ethanol, butanol, ethyl acetate, butylacetate, in a mixture of chlorinated hydrocarbons and insoluble in aliphatic hydrocarbons (in petrol). The density of the polyvinyl butyral used in the research was $1,07 \mathrm{~g} . \mathrm{cm}^{-3}$, and the recyclable price of the recyclate was $0,25 €$ to $0,50 €$ per kilogram.

\section{Laboratory testing of the recycled polyvinyl butyral}

The use of pressing technology from a comprehensive point of view, is still today among the simplest and economically acceptable thermoplastic or thermoplastic processing technologies at all. [12]

The pressing task is to form the molten polymer in the cavity of the die. In the case of the molding of samples formed by recycled polyvinyl butyral, the thermoplastic material was melted in the mold cavity, material has reached a melting point temperature (Tm). [4] Continuous mixing was used to prepare the homogenized mixture. Continuous mixing provided complete homogenization of the material. Homogenization of the material was carried out on a Brabender PlastiCorder W 350 E (Fig.4). Tests were performed at room temperature $22^{\circ} \mathrm{C}$ and $60 \%$ humidity. [11] The homogenization process lasted $15 \mathrm{~min}$. At the time of the time, the material was thoroughly mixed to prevent the formation of air bubbles that were undesirable in the molding process (resulting from compression, imperfect mixing or incomplete filling of the thermoplastic mold cavity). 


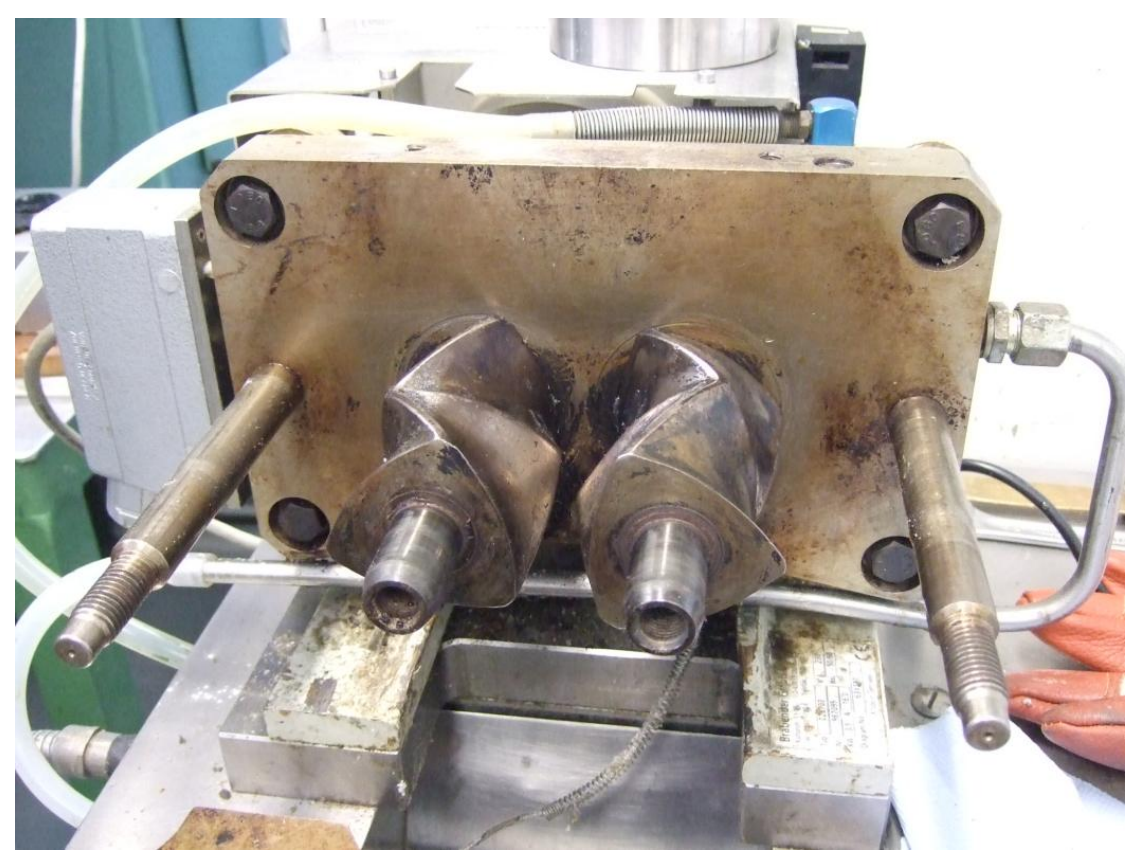

Fig.4. Homogenization of recycled polyvinyl butyral by Brabender Plasti-Corder W $350 \mathrm{E}[12]$

\subsection{Pressing of the recycled material}

After homogenization of recycled polyvinyl butyral on a Brabender PlastiCorder W 350 E, the material was carefully selected and ready to be pressed. Prior to molding, the mold was cleaned, minimizing impurities. [13] , [14] The stamping was carried out on a laboratory press equipment Brabender W 350. The press cycle was composed of the following operations:

- mold opening,

- filling the mold with a material,

- mold closure,

- Self-pressing,

- mold opening,

- removal of the mold,

- cooling the mold,

- cleaning the mold cavity.

Table 2 contains a pressing conditions of the recycled polyvinyl butyral by Brabender W 350 . 
Table 2. Pressing conditions of the recycled polyvinyl butyral

\begin{tabular}{|l|l|}
\hline Press equipment & Brabender W 350 \\
\hline Press temperature & $190^{\circ} \mathrm{C}$ \\
\hline Pre-heating time & $20 \mathrm{~min}$ \\
\hline Pressing time & $20 \mathrm{~min}$ \\
\hline Cooling time & $20 \mathrm{~min}$ \\
\hline Pressure & $10 \mathrm{MPa}$ \\
\hline
\end{tabular}

As mentioned above, after completion of the homogenization, test plates were pressed from which, according to DIN EN ISO 527-1, samples of type No.5 were pressed. Thus, the samples were prepared according to the standard, [15] they were ready for testing Mechanical properties of the material, by means of a tensile test. The tensile test (Fig.5) evaluated the tensile strength of the material.

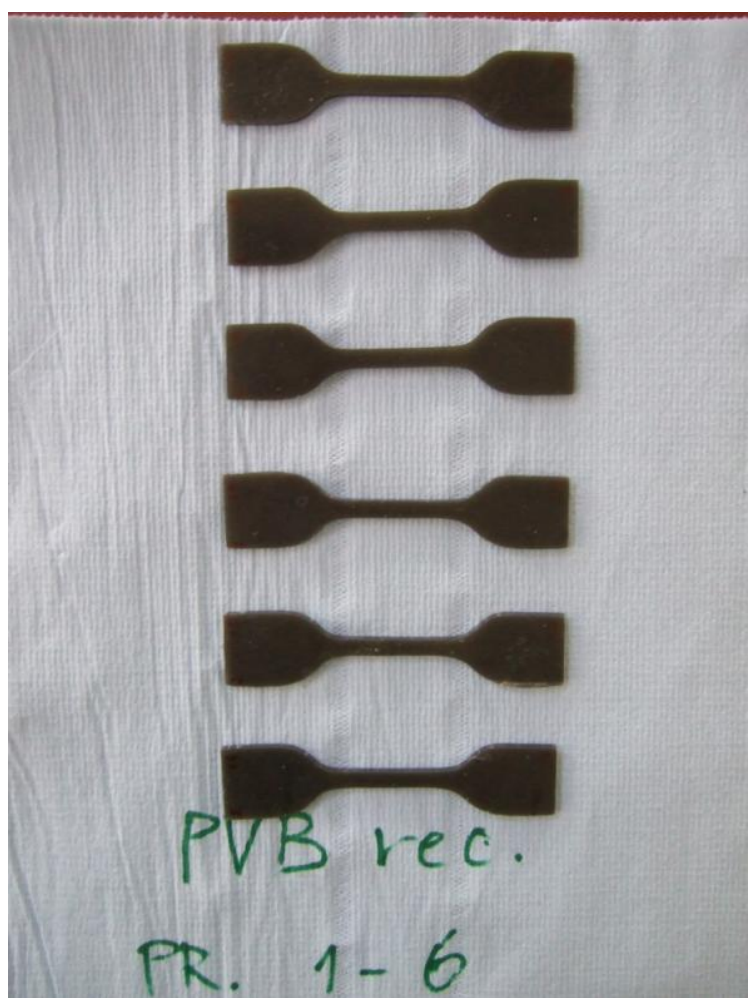

Fig.5. Tensile test samples [12]

The test principle consisted of stressing the test body until the sample breaks. The test samples ware clamped into the jaws of the tensile test machine. 


\section{Conclusion}

The advantage of this paper is the application of recycled materials. An important aspect of the processed issue was the

- $\quad$ protection of the environment and

- the searching of environmentally acceptable ways of processing this commodity.

At the beginning of the work, carried out in the current state of the problem solved, the application of materials was designed to the automotive industry (not only there). The use of materials from recycled polyvinyl butyral, especially composite materials based on recycled polyvinyl butyral, thus confirms the demand for these materials.

Realizing the processed problem it was found new applications ways for material, that can be used as a:

- $\quad$ possible substitute for selected components of engineering production.

- possible substitute for automotive production

- possible substitute for electro technical production

\section{References}

[1] Patent, No. DE 10301738A1, Vefahren and Vorrichtung zur vollstandigen Glassbefreiung von restglas behafteter PVB-folia aus der Verbundsicherheitsglasaufbereitung.(in german)

[2] Jeluš ,M. Auto Glass Recycling.. [online], Cited [13.07.2016] (2016)

[3] Patent, No. EP 1375017A, Glass fragment recovering method.

[4] Patent, No. DE 10200602351A1, Verfahren zum Verwentung von Problemflachgläsern, Verfahren zur Herstellung von Schaumglas und Verfahren zur Aufbereitung von Problemglasflachen.(in german)

[5] Patent, No. US9028644B2, Method for producing glass laminates with sound attenuating properties

[6] Schirmbeck GmbH, [online], Cited [13.07.2016], Available on WWW $<$ http://www. http://www.schirmbeck.com/> (2016)

[7] Utility model, No. SK1682013U1, Kompozitný materiál z recyklovaných textílií. In Slovak (2013) 
[8] Transparency market research [online], Cited [10.08.2016].Available on WWW $<$ http://www.transparencymarketresearch.com/polyvinyl-butyral-filmssheets.html> (2016)

[9] Polyvinyl butyral [online], Cited [08.08.2016]. Available on WWW< https://www.ihs.com/products/polyvinyl-butyral-chemical-economicshandbook.html> (2016)

[10] Dhaliwal, A. K.; Hay, J. N. The characterization of polyvinyl butyral by thermal analysis". Thermochimica Acta. 91: 245-255. doi:10.1016/s0040-6031(02)00187-9 (2002)

[11] Barry, C.M.F., Orroth, S.A.:Processing of thermoplastics, In: Harper, CH.A.: ModernPlastics Handbook, USA, ISBN 0-07-026714-6 (2000)

[12] Knapčíková ,L. Optimalizácia technologických procesov pri zhodnocovaní plastov, Dizertačná práca,FVT TUKE. In Slovak. (2011)

[13] Sekisui chemical.com. [online], Cited [20.02.2016] Available on WWW <www. Sekisui chemical.com>.(2016)

[14] Hutyrová ,Z., et.al. Turning of wood plastic composites by water jet and abrasive water jet, In: The International Journal of Advanced Manufacturing Technology. Vol. 84, no. 5-8, p. 1615-1623. - ISSN 0268-3768 (2016)

[15] Wang, W., Koren, Y.Scalability planning for reconfigurable manufacturing systems. Journal of Manufacturing Systems 31, p.83-91 (2012) 